\title{
LEITURA E DISCUSSÃO DE OBRAS INDÍGENAS E INDIGENISTAS EM ESPANHOL: UM RELATO DE EXPERIÊNCIA EM AÇÃO EXTENSIONISTA
}

\author{
Lectura y discusión de obras indigenas e indigenistas en español: un \\ informe de experiencia en acción extensionista
}

\author{
Ana Paula Marques BEATO-CANATO \\ Universidade Federal do Paraná \\ anabeatocanato@gmail.com \\ https://orcid.org/0000-0001-9682-1644 \\ Rogério BACK \\ Programa de Pós-Graduação em Letras \\ Universidade Federal do Paraná \\ backruz@hotmail.com \\ https://orcid.org/0000-0002-1520-5290
}

\begin{abstract}
RESUMO: Em tempos agressivos, oriundos de pensamentos positivistas, coloniais e excludentes, diversos saberes e culturas têm sido propositalmente colocados à margem da sociedade civil e, por conseguinte, do ambiente escolar. Nessa esteira, embora haja legislação específica que exige a valorização das culturas indígenas e afro-brasileiras (BRASIL, 2008), a formação docente ainda deixa a desejar no que concerne ao favorecimento do conhecimento das diversas culturas e diferentes cosmovisões, como a dos povos indígenas (SILVA; COSTA, 2018). Visando contribuir para a ampliação da discussão e quiçá para a formação de professoras/es, em 2020, ofertamos a oficina Leitura e discussão de obras indigenas e indigenistas em espanhol. Neste relato, objetivamos trazer um panorama e reflexões sobre tal ação extensionista. Desde nossas impressões e dados gerados na oficina, a proposta é discutir como as literaturas indígenas podem potencializar que aspectos socioculturais e identitários indígenas sejam o centro do processo de ensino-aprendizagem em uma perspectiva intercultural (WALSH, 2009). Após uma série de encontros focados em leituras literárias de autoria indígena, avaliamos que o ensino de línguas com foco em aspectos culturais pode constituir-se como uma forma de aproximação,
\end{abstract}

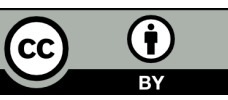


valorização da diversidade e ressignificação da luta e do imaginário dos diferentes povos indígenas por meio de suas produções literárias. PALAVRAS-CHAVE: Povos indígenas; Literaturas indígenas; Relato de experiência; Língua espanhola.

RESUMEN: En tiempos agresivos, emergidos de pensamientos positivistas, coloniales y excluyentes, variados saberes y culturas han sido colocados al margen de la sociedad civil y del ámbito escolar. Aunque haya legislación específica que exige la valorización de las culturas indígenas y afrobrasileñas (BRASIL, 2008), la formación docente suele no favorecer el conocimiento acerca de las diversas culturas y cosmovisiones, como la de los pueblos indígenas (SILVA; COSTA, 2018). Con el objetivo de contribuir a la expansión de la discusión y quizás a la formación de profesores, en 2020, ofrecimos el taller Lectura y discusión de obras indígenas e indigenistas en español. En este informe, pretendemos aportar una visión general y reflexiones sobre dicha acción. Desde nuestras impresiones y datos generados en el taller, discutiremos cómo las literaturas indígenas pueden potenciar que los aspectos socioculturales e identitarios indígenas se vuelvan el centro del proceso de enseñanza-aprendizaje en una perspectiva intercultural (WALSH, 2009). Tras una serie de encuentros centrados en lecturas literarias de autoría indígena, evaluamos que la enseñanza de lenguas con enfoque en aspectos culturales, puede constituirse una forma de aproximación, valoración de la diversidad y resignificación de la lucha y el imaginario hacia los pueblos indígenas a través de sus producciones literarias. PALABRAS-CLAVE: Pueblos indígenas; Literaturas indígenas; Informe de experiencia; Lengua española.

\section{CONTEXTUALIZANDO O RELATO}

Em meio a uma pandemia que ceifa milhares de vidas, vivemos tempos de ebulição histórica, política e social, que nos incitam a repensar a perspectiva pela qual vivemos e atuamos pessoal e profissionalmente, e a avaliar se nossas ações têm potencial para contribuir com a manutenção ou a desestabilização de narrativas hegemônicas que beneficiam certa parcela da população enquanto outros saberes e culturas são propositalmente colocados à margem da sociedade civil e, por conseguinte, do ambiente escolar. Nesse contexto, defendemos a necessidade de formação de professoras/ es de todas as áreas do saber engajadas/os com questões sociais e comprometidas/os com pedagogias que valorizem diferentes formas de ser e saber e contribuam para a diminuição de violências e sofrimentos. Ou seja, advogamos a favor da interculturalidade como princípio que orienta pensamentos, ações e enfoques epistêmicos (WALSH, 2005). 
Foi com o intuito de contribuir com esse processo que, em 2020, ofertamos a oficina Leitura e discussão de obras indígenas e indigenistas em espanhol, como curso livre atrelado ao programa de pós-graduação ao qual estamos vinculada/os. Nesse texto, temos a intenção de traçar um panorama da ação extensionista e trazer reflexões sobre os resultados alcançados e os potenciais de ações dessa natureza como projetos em prol da interculturalidade e da decolonialidade propostas por Walsh (2009), entendendo interculturalidade como "processo e projeto dirigido à construção de modos 'outros' do poder, saber, ser e viver [que] permite ir muito além dos pressupostos e manifestações atuais da educação intercultural bilíngue ou da filosofia intercultural" (WALSH, 2009, p. 23-24).

Para isso, organizamos o relato em sete partes. Feita essa contextualização inicial, na próxima seção, problematizamos a história única na qual nos vemos inseridos e indicamos a necessidade e a potencialidade de ações extensionistas e ferramentas pedagógicas interculturais e decoloniais. Nas partes seguintes, descrevemos e avaliamos o curso, narrando como cada um dos seis encontros foi inicialmente idealizado e posteriormente ajustado a cargo da pluralidade de participantes inscritas/os. Nas partes finais, perfazemos uma análise crítica de todo o processo e apontamos como cursos dessa natureza têm potencial para ressignificar identidades e lutas e construir diálogos urgentes e necessários nos dias atuais.

\section{PROBLEMATIZANDO A HISTÓRIA ÚNICA NA QUAL NOS INSERIMOS}

Apagamentos! Invisibilidade! Inviabilidade! Negação! Binarismos! Extermínio étnico, racial, religioso, linguístico, epistêmico e cultural! Expressões, termos, visões e ações agressivas e violentas como estas fizeram e fazem parte de uma história única (GRAÚNA, 2011; ADICHIE, 2009), construída e narrada desde o ponto de vista de grupos hegemônicos que excluem e negam a pluralidade de saberes, culturas, modos de ser e viver para impor sua forma como se fosse a única, a correta, a melhor. $\mathrm{Na}$ contramão dessas narrativas impostas, alguns grupos sociais, como indígenas, africanos, afro-brasileiros e imigrantes, para citarmos apenas alguns exemplos, têm resistido e reexistido (SOUZA, 2011), insistindo em manter suas formas de vidas e continuar construindo outras histórias.

Para o quilombola Antônio Bispo dos Santos (2015), independentemente de suas especificidades quanto ao processo de escravização, povos originários das Américas e oriundos da África são contracolonizadores. Neste sentido, o autor cunha o termo contra colonização (e seus derivados contracolonizalidade e contracolonial). Para ele, "vamos compreender por contra colonização todos os processos de resistência e de luta em defesa 
dos territórios dos povos contra colonizadores, os símbolos, as significações e os modos de vida praticados nesses territórios" (SANTOS, 2015, p. 48).

Frutos de constantes mobilizações e articulações contracoloniais dos povos afro-pindorâmicos ${ }^{1}$, algumas conquistas históricas têm sido concretizadas, sobretudo a partir da Constituição Federal (BRASIL, 1988), que reconhece a pluralidade do povo brasileiro e garante ao indígena o direito a falar suas línguas e ter sistemas educacionais próprios. No âmbito educacional, outra conquista importante é a Lei 10.639 (BRASIL, 2003) que torna obrigatória a inserção da temática da história e cultura afro-brasileira em todo o currículo escolar. Mais tarde, a Lei 11.645 (BRASIL, 2008) modifica a legislação de 2003, acrescentando a cultura e história dos povos indígenas nos currículos dos estabelecimentos escolares públicos e privados do país. Legislações como essas, além de valorizarem a riqueza cultural que permeia nosso país, podem contribuir para a ressignificação de identidades "periféricas", trazendo um olhar mais amoroso e empático a essas populações.

Contudo, em 2011, três anos após a Lei de 2008, a professora e pesquisadora Graça Graúna, do povo Potiguara, já apontava as dificuldades de implementação da temática indígena no âmbito das escolas não indígenas. Em seu estudo, Graúna (2011) perfaz um compilado de posicionamentos de professoras e professores indígenas de variados povos quanto à real aplicabilidade da normativa. Dentre alguns depoimentos, destacamos algumas falas recorrentes, como aquelas relacionadas ao fato de os livros didáticos trazerem a imagem de um indígena homogêneo e estereotipado; do desconhecimento, por parte da população nacional, acerca da pluralidade de povos e línguas originárias; da necessidade de se conhecer outros lados da história do "descobrimento" do Brasil, entre muitas outras problematizações.

Uma das professoras entrevistadas por Graúna (2011), Marize de Oliveira Pinto (nome indígena Tamikuan Ará), do povo Guarani, cita quatro ações urgentes e necessárias para a real aplicação da Lei 11.645 (BRASIL, 2008), sendo elas:

(1) garantir cursos de capacitação para os professores (eles não trabalharão com algo que não acreditam ser importante para o processo de ensino-aprendizagem, e se acreditarem nesta importância não trabalharão com este tema sem ter segurança sobre aquilo que sabem para poder passar); (2) garantir material sobre a questão indígena

\footnotetext{
${ }^{1}$ Junção dos termos africanos e pindorâmicos. Bispo dos Santos (2015) nomeia os povos indígenas brasileiros de pindorâmicos, termo emergido de Terra de Pindorama (Terra das palmeiras), como eram chamadas as terras que vieram a se chamar Brasil por parte dos povos de língua tupi que aqui habitavam antes da invasão europeia.
} 
e livros escritos pelos indígenas (literatura, textos, trabalhos) para consulta nas escolas. Quer seja pelos professores, quer seja pelos alunos (informação é fundamental para quem quer trabalhar); (3) disponibilizar cursos de formação continuada sobre a questão indígena. Isto manterá os professores debatendo constantemente esta questão. (4) garantir que as universidades públicas, principalmente, abram pósgraduações e outras especializações sobre a questão indígena visando à capacitação dos professores, visando à sala de aula (TAMIKUAN ARÁ in GRAÚNA, 2011, p. 248-249).

Do depoimento de Tamikuan Ará destacamos a necessidade de a formação inicial e/ou continuada de professoras/es ser pautada, também, nas relações étnico raciais, e indicamos a imprescindibilidade de que esse trabalho aconteça a partir de histórias, literaturas, epistemologias, cosmovisões e tradições, visando a aproximação com os povos indígenas e possibilitando o conhecimento de suas especificidades. Neste sentido, entendemos não caber discussões que falam "sobre" os sujeitos sociais historicamente marginalizados, ou seja, não pertencentes aos grupos hegemônicos (SANTOS, 2007), mas sim, que dialoguem com indígenas, quilombolas, afro-brasileiros, em movimentos que incitem questionamentos e transformações de relações de poder, saber e ser, tornando visíveis e possíveis outras formas de pensar, diferentes da lógica eurocêntrica dominante (WALSH, 2005).

Conforme apontam Silva e Costa (2018), passados dez anos que a Lei 11.645/08 foi sancionada, ainda há muito o que fazer nas escolas brasileiras para que, de fato, haja a valorização da cultura indígena no âmbito escolar e na sociedade civil como um todo em prol de intercâmbios que promovam o desenvolvimento de novos sentidos nas diferenças, como propõe Walsh (2001). Para os autores citados, muitas vezes a aplicação da normativa somente se dá no mês de abril, sobretudo no "dia do índio", sendo que a grande maioria das/os professoras/es "sequer sabem porque esta data é dedicada aos indígenas" (SILVA; COSTA, 2018, p. 68). Nesse contexto,

[i]nvariavelmente, professores e alunos se veem envoltos em atividades que reproduzem estereótipos e pouco acrescentam à formação de crianças e jovens, que continuam a ver os indígenas como aqueles que andam nus ou apenas vestem tangas, possuem colares e cocares, falam línguas estranhas e estão distantes do "grau de civilização" dos não índios (SILVA; COSTA, 2018, p. 68).

Assim como já apontava Tamikuan Ará em 2008, Silva e Costa (2018) sustentam a necessidade de diálogo intercultural, epistêmico e de aproximação com povos e pessoas 
indígenas. Ademais, argumentam que os saberes e temáticas ancestrais não devem ser trabalhados de maneira folclorizada e/ou somente no mês destinado aos povos indígenas. Daí a necessidade de cursos de capacitação e formação continuada sobre a temática indígena guiada, supervisionada e/ou com a participação de pessoas indígenas, que, a partir de suas vivências, somarão forças para um melhor cumprimento da Lei.

Em nossas vivências, temos tentado cada vez mais nos aproximar, dialogar, aprender e construir junto com os povos indígenas. Nesta esteira, temos defendido que as literaturas indígenas, por serem plurais, diversas, heterogêneas, além de abarcarem diferentes temáticas e discussões,

[...] auxiliam a nos aproximar de diferentes povos, seus processos de perdas das terras, seguido por movimentos de ocupação de um entrelugar cultural e ideológico. Essa aproximação de maneira não estereotipada pode contribuir para a desestruturação sistemática de uma narrativa colonial pautada em princípios de unidade e pureza. Ainda, tem força contra o conceito de desindianização e a compreensão de que o indígena, aonde quer que vá, leva dentro de si a aldeia e não deixa de ser ele mesmo quando entra em contato com o outro (não indígena) ainda que more na cidade, use tecnologias, se vista com jeans, como assevera Graúna (2013). (BACK; BEATO-CANATO; AMORIM, 2021, p.1035).

Cabe ressaltar que não objetivamos, neste texto, aprofundar as discussões teóricas acerca do que se convencionou chamar de literatura indígena, mas sim, perfazer um relato de experiência em uma ação extensionista. Contudo, acreditamos ser necessário diferenciar, ainda que brevemente, as literaturas indígenas das indigenistas e indianistas. Em nosso entendimento, literaturas indígenas - e/ou literaturas nativas - são:

Produções artístico-literárias compostas necessariamente por pessoas indígenas. Tais obras são heterogêneas tanto na forma quanto no conteúdo, podendo, em seus eixos temáticos, abarcar questões étnicas (cosmovisões, valores, tradições, lutas, resistências, processos de desterritorialização e desealdeamento), subjetivas (sentimentos, afetos, emoções), identitárias (sentimento de não pertencimento, por exemplo) e/ou sociais (alcoolismo, drogas, violência, suicídio). Já as produções conhecidas como indigenistas, em linhas gerais, são aquelas que falam sobre os indígenas - seus modos de ser e outros temas relacionados -, de forma a dialogar com a luta dos diferentes povos, ademais de favorecer o protagonismo indígena. Diferente da anterior, estas produções são de autoria não indígena. [...] Por sua vez, a literatura indianista é aquela que traz a figura do indígena como o "bom selvagem" e herói nacional. São obras que, na maioria das vezes, romantizam a figura ameríndia, 
além de serem dotadas de certo teor estereotipado na construção dessas identidades, por vezes, caracterizando-os como preguiçosos e não civilizados (BACK; BEATO-CANATO; AMORIM, 2021, p.1029-1030).

Dito isto, com vistas a engrossar as discussões e quiçá contribuir com a formação de professoras/es em meio a uma pandemia mundial, idealizamos e ofertamos, em 2020, de forma remota, o curso de extensão objeto desse relato de experiência. Cientes, porém, que enquanto branca/os (no sentido não indígenas), corremos riscos de que nossas escolhas linguísticas, teóricas e metodológicas possam (re)produzir, ainda que inconscientemente, narrativas coloniais, procuramos dialogar, nos aproximar e estender o convite a indígenas para que junta/os guiássemos os encontros de discussão. Assim, a partir da próxima seção, traremos um panorama do curso, desde seus objetivos até nossa avaliação crítica desta oferta extensionista.

\section{O CURSO LEITURA E DISCUSSÃO DE OBRAS INDÍGENAS E INDIGENIS- TAS EM ESPANHOL}

Ofertados de forma gratuita e configurando-se como uma dimensão extensionista de pesquisas em desenvolvimento, os Cursos Livres (CLs) são ações organizadas pela representação discente em parceria com a coordenação do Programa de Pós-graduação em Letras da Universidade Federal do Paraná (UFPR) e constituem-se como grupos de leitura e/ou oficinas concebidos e ministrados por mestrandas/os e doutorandas/os do programa, com supervisão de suas/seus orientadoras/es.

Em 2020, a cargo do isolamento social e de todas as nuances decorridas da pandemia mundial, as ações foram realizadas de forma remota, o que possibilitou o alcance de um público diverso. Nesse contexto, o curso Leitura e discussão de obras indigenas e indigenistas em espanhol foi realizado entre os dias 14 de julho e 18 de agosto de 2020, com carga horária de vinte horas, divididas em seis encontros síncronos de duas horas cada e oito horas destinadas à leitura e preparação de uma apresentação final.

O objetivo geral do curso foi fomentar a leitura e a discussão de textos literários em língua espanhola a partir de obras indígenas e indigenistas selecionadas. Como objetivos específicos, procurou dialogar com diferentes autoras/es indígenas e indigenistas latinoamericanas/os e discutir temáticas, lutas, saberes e cosmovisões indígenas plurais por meio dessa seleção. A ação foi ofertada a toda a comunidade (tanto interna quanto externa à universidade), objetivando, também, popularizar a literatura indígena entre a população não indígena, independentemente dos conhecimentos de língua espanhola. 
As atividades aconteciam às terças-feiras, das 18 às 20 horas e, para esses encontros, as/os cursistas deveriam realizar leituras prévias de forma assíncrona. Como o curso foi idealizado como grupo de leitura, as aulas ocorreram de modo dialogado entre todas/os as/os participantes, diálogo esse fomentado pelas leituras propostas.

Ao ministrante ${ }^{2}$ coube guiar as discussões e preparar materiais que estabelecessem uma ponte entre as/os participantes e as leituras, como pesquisas sobre o local de fala das/dos escritoras/es apresentadas/os, o povo a que pertence, nacionalidade e outras informações pertinentes. Por sua vez, coube à/os cursistas realizar leituras prévias e participar ativamente das discussões nos encontros. As intervenções ocorreram tanto na língua portuguesa como espanhola, a depender das atividades e do maior conforto por parte das/os cursistas. Por outro lado, todas as leituras (básicas e complementares) eram em língua espanhola. A seguir, trazemos informações mais detalhadas sobre o curso.

\section{PLANEJAMENTO DO CURSO}

Pensar uma América Latina multicultural é também pensá-la desde a pluralidade de povos e línguas indígenas. Dessa forma, a seleção do material para os seis encontros foi planejada de modo a abarcar a variedade estética e temática de variados povos originários, procurando contribuir para a desconstrução de visões genéricas, homogeneizadas e estereotipadas em prol de ressignificações e valorização de diferentes modos de ser e saber.

Dentre os temas escolhidos para o debate síncrono temos: diferenciação da literatura indígena e indigenistas (semelhanças e contrastes); ressignificação da identidade indígena por meio da sua literatura em língua espanhola; discussão da pluralidade identitária dos diferentes povos originários latino-americanos; abordagem da luta e o modo de viver e ser destes povos e o estabelecimento de um diálogo com os indígenas, em detrimento de sobre eles. Abaixo, transcrevemos um recorte do planejamento inicial do curso, o qual sofreu alterações, especialmente após o primeiro encontro, visando adequar-se às expectativas e demandas das/os participantes.

\footnotetext{
${ }^{2}$ Conforme apontamos no primeiro parágrafo desta seção, os cursos livres são ministrados por pós-graduandas/os do Programa de Pós-graduação em Letras (UFPR) e supervisionados por suas/seus orientadoras/es. Assim, no caso específico da oficina que relatamos, informamos que Rogério Back, na condição de mestrando, se constituiu o ministrante principal do curso ofertado e Ana Paula Marques Beato-Canato, enquanto orientadora, colaborou e acompanhou de perto todas as etapas realizadas (planejamento, organização e execução das atividades). Cabe destacar que Rogério é licenciado em Letras: Espanhol (UFSC) e sua atual pesquisa versa sobre a temática e os saberes indígenas integrados no processo de ensino-aprendizagem da língua espanhola.
} 
Quadro 1: Cronograma de execução das atividades síncronas (via Teams).

\begin{tabular}{|c|c|}
\hline Data & Descrição das atividades \\
\hline $\begin{array}{l}1^{\circ} \text { encontro } \\
14 / 07 / 2020\end{array}$ & $\begin{array}{c}\text { Apresentação } \\
\text { Apresentação da proposta do curso e das/os participantes; } \\
\text { Vídeo: Literatura en tiempos de pandemia; } \\
\text { Obras a serem trabalhadas: El enemigo verdadero e Por primera vez en mi vida } \\
\text { envío una carta, de Jairo Anibal Niño e fragmento de Bartaburu e Oliveyra } \\
\text { (2004). }\end{array}$ \\
\hline $2^{\circ}$ encontro & $\begin{array}{c}\text { Contos e lendas indígenas parte } 1 \\
\text { Obras a serem lidas e discutidas: } \\
\text { La niña del Río (Conto de tradição popular Chinanteco) } \\
\text { Lino Trinidad Sanabria - El maiz; } \\
\text { Francisco Cardoso - Pedrito. }\end{array}$ \\
\hline $\begin{array}{l}3^{\circ} \text { encontro } \\
28 / 07 / 2020\end{array}$ & $\begin{array}{c}\text { Contos e lendas indígenas parte } 2 \\
\text { Leitura, discussão e problematização de contos selecionados da obra Histórias } \\
\text { de um guaraní, de Nelson Florentino. }\end{array}$ \\
\hline $\begin{array}{l}4^{\circ} \text { encontro } \\
04 / 08 / 2020\end{array}$ & $\begin{array}{l}\text { Contos indigenistas } \\
\text { Obras a serem lidas e discutidas: } \\
\text { Horacio Quiroga - La guerra de los yacares; } \\
\text { Josefina Plá - El gigante invisible. }\end{array}$ \\
\hline $\begin{array}{l}5^{\circ} \text { encontro } \\
11 / 08 / 2020\end{array}$ & $\begin{array}{c}\text { Novela indígena } \\
\text { Obra a ser lida e discutida: } \\
\text { Marisol Ceh Moo - Sujuy k'iin: día sin mancha. }\end{array}$ \\
\hline $\begin{array}{l}6^{\circ} \text { encontro } \\
18 / 08 / 2020\end{array}$ & $\begin{array}{c}\text { Encerramento do curso } \\
\text { Sarau literário. }\end{array}$ \\
\hline
\end{tabular}

Fonte: elaboração própria.

Cabe pontuar que o curso teve uma obra principal, a novela Sujuy k'iin: dia sin mancha, de Sol Ceh Moo, escritora indígena do povo Maya Yacuteco, sendo as demais leituras consideradas fomentadoras do diálogo. Encerrando as atividades, o último encontro se deu em forma de um sarau literário, momento em que as/os cursistas trouxeram e performaram suas próprias leituras de obras com autoria indígena. 


\section{RELATO DAS ATIVIDADES}

\section{$1^{\circ}$ Encontro}

No primeiro encontro, visávamos introduzir a temática do curso e sensibilizar as/os participantes para a leitura e discussão de textos literários indígenas e indigenistas em língua espanhola. Também intencionávamos conhecer as/os participantes e avaliar seus conhecimentos e as expectativas para que o curso pudesse ser conduzido de modo a contribuir com o grupo da melhor maneira possível.

Para o primeiro dia, não foi exigida leitura prévia e o encontro foi iniciado com explanações sobre a ementa, o funcionamento do curso e uma breve apresentação de alguns dados sobre a população indígena latino-americana. Em seguida, para cotejar o grau de imersão do grupo ao universo dos povos indígenas, foi realizada uma dinâmica norteada pelas seguintes questões: Para você, o que é ser uma pessoa indígena? Quais imagens evoca? Conhece, lê e sabe diferenciar literatura indígena de indigenista?

As participações indicam graus de proximidade variados, em um grupo que se constitui interculturalmente, tendo desde liderança indígena, que se vê "como ser resistente, que vem da natureza, ao mesmo tempo um ser que tem sintonia com a natureza protegendo-a e ampliando o bem viver as demais sociedades" (Cursista A), a participantes que se percebem distantes, mas com desejo de conhecer mais, como ilustram algumas das falas que reproduzimos a seguir:

- Pessoas indígenas: um estilo de vida que engloba respeito à natureza, uma forma de viver e enxergar o mundo (Cursista $\mathrm{B}$ ).

- Povos originários das Américas e eles me evocam imagens de qualidade de relação interpessoal e com a natureza (Cursista $\mathrm{C}$ ).

- Povos originários das terras colonizadas. Na verdade, sei muito pouco sobre esses povos antes dos processos de colonização, então acabo por ter uma imagem desses povos fortemente influenciada pelo discurso dos grupos hegemônicos. Gostaria muito de saber mais sobre as cosmologias indígenas (Cursista D).

- Algumas imagens traduzidas em palavras: Brasil/ Amazônia/ Natureza/ Originalidade/Beleza/Rituais (Cursista E). 
- Pessoa pertencente à uma comunidade indígena, mas que não necessariamente viva numa aldeia. Está mais relacionado a subjetividade humana. Como sua relação com o mundo, crenças e práticas... (Cursista F).

- Pessoas indígenas me evocam imagens de ancestralidade, resistência, luta, conhecimentos, saberes únicos e muita ciência. Sobretudo, vejo como povos e etnias diversas, dotadas de singularidades e subjetividades naturais das construções identitárias dos indivíduos (Cursista G).

Notamos nas falas das/os participantes a compreensão da diversidade identitária dos povos indígenas e a valorização de suas histórias e cosmovisões, especialmente no que concerne à relação com a natureza. Apontamos também a valorização de suas resistências, lutas e saberes bem como o desejo por saber mais, contexto propício para o desenvolvimento de nossa proposta, que procura valorizar a diversidade e as diferenças e ressignificar saberes sobre indígenas desde uma perspectiva intercultural em prol de uma pedagogia do pensar com, ou seja, um processo educativo que assume a responsabilidade e compromisso de transformação, construção de um projeto político social epistêmico e ético da interculturalidade em que caibam todos (WALSH, 2009).

Sobre as autoras e autores mencionados pelas/os participantes, temos: Márcia Kambeba; Julie Dorrico; Eliane Potiguara; Graça Graúna; Ailton Krenak; Geni Ñunes; Kaka Werá Jecupé; Aline Rochedo Pachamama. Embora sejam escritoras e escritores já editoradas/os, algumas/alguns conhecidas/os do grande público, avaliamos como nomes que precisam ser lidos e discutidos em todas as esferas sociais e escolares, dada a relevância de seus trabalhos.

Após a discussão inicial sobre a proximidade com a cultura indígena, foram expostas algumas fotos de indígenas brasileiras/os para que fosse possível ampliar o diálogo. As imagens incluíam desde lideranças bastante conhecidas, como Ailton Krenak, a indígenas em contexto urbano, rappers, youtubers, indígenas LGBTQIA+, ilustrando a complexidade das identidades indígenas constituídas de forma interseccional (HALL, 2015 [1992]). A dinâmica visava quebrar estereótipos e sugerir um novo olhar para o indígena contemporâneo, a pluralidade identitária, linguística e cultural e o reflexo dessas diferentes cosmovisões em seus escritos literários.

Antes de passar para a descrição do segundo encontro, é importante destacar que, a partir da lista de inscritas/os e do primeiro encontro, alguns ajustes na ementa foram realizados para melhor atender ao perfil das/os cursistas. Inicialmente, tínhamos como público-alvo participantes que visassem um primeiro contato com a literatura indígena 
e indigenista latino-americana em língua espanhola. Contudo, embora algumas/alguns cursistas tivessem esse perfil, nos deparamos com um grupo bastante diversificado, englobando pesquisadoras/es, acadêmicas/os e professoras/es da educação básica à pósgraduação, pessoas de diversas partes do Brasil, da Argentina e do Peru, unidos por um pensamento contra/decolonial e por interesses prévios que dialogavam de alguma forma com o propósito do curso. Ademais, houve matrículas de pessoas indígenas, inclusive lideranças, que contribuíram demasiadamente com o curso livre.

Dentre as mudanças realizadas, talvez a mais significativa tenha sido o convite a algumas/alguns participantes para ocuparem um espaço de fala para compartilhar com o grupo suas experiências enquanto mediadoras/es de literaturas indígenas, ademais de relatar suas vivências junto a povos com os quais essas/es cursistas tinham alguma proximidade. Além dessa modificação, outras alterações realizadas foram: não centrar as discussões totalmente nos textos lidos, mas perfazer um paralelo das leituras com os relatos de cada participante e diminuir a carga de leitura prévia para que o debate nos encontros síncronos fosse mais aprofundado e problematizado. Todos esses ajustes, além de fortalecer o grupo, contribuíram, também, para a criação de vínculos afetivos, sentimento esse muito valorizado no momento de aproximação com os povos originários.

\section{$2^{\circ}$ Encontro}

O encontro contou com três momentos, tendo como objetivos discutir as identidades indígenas e introduzir a literatura indígena. Para isso, dados legais e de órgãos nacionais e internacionais foram debatidos e foram discutidos quatro contos e lendas indígenas, ilustrativas de diferentes vertentes, como veremos mais adiante.

Tendo como intenção dar continuidade à desmistificação do imaginário popular, que comumente associa o indígena ao ser exclusivamente selvagem morador de aldeias, como se todos fossem iguais, no início do encontro, foram compartilhados excertos de comentários feitos pelo grupo no encontro anterior a respeito do que é ser indígena. A partir disso, esses olhares foram confrontados com as normativas da Fundação Nacional do Índio (FUNAI) e legislações internacionais que determinam o que é ser indígena. Dentre as possibilidades legais para que uma pessoa seja considerada indígena, duas desconhecidas do grupo eram: o matrimônio e a moradia em um lar cujo chefe seja indígena. As informações foram enriquecidas com compartilhamentos de conhecimentos de integrantes do grupo, caso de um argentino que expôs que, em seu país, a situação é similar e ainda que a consciência de pertencimento, ou seja, a autodeclaração, também é fator determinante. 
O segundo momento do encontro teve foco no debate das quatro obras selecionadas e lidas previamente pelas/os cursistas, as quais são características de duas vertentes da literatura indígena. Intitulada La niña del río - cuento de tradición popular Chinanteco (povo Chinanteco - México), a primeira obra, narrada em língua nativa e traduzida ao espanhol, conta a história de uma pequena garotinha que não queria casarse por imposição de seus pais. Todos os dias ela ia ao rio chorar pelo seu destino prédeterminado. Certo dia, inconformada com a situação, decidiu converter-se em parte do rio, provando que cada qual é dono de seu próprio destino. Já a segunda obra, El maíz, de Lino Tranidad Sanabria (povo Guarani - Paraguai), aborda as origens do milho. Certa vez, uma flecha, que não se sabe de onde partiu, acabou por tirar a vida de uma bela indígena Guarani. Abatido, todos os dias, seu amado levava a sua sepultura uma planta diferente. Destacando-se das demais, uma das plantas cresceu tanto a ponto de dar frutos com belos cabelos dourados que remetiam aos da indígena morta. Assim, os Guarani entenderam que a morte veio para alimentar o povo que carecia de alimento naquelas épocas.

Desde essas duas narrativas, apontamos uma das vertentes das literaturas indígenas: narrar histórias ancestrais e modos tradicionais de cada povo. No momento de discussão, muitos se posicionaram sobre o papel da mulher indígena, da cosmovisão e dos mitos de criação, ponto mais debatido. A esse respeito, professoras/es falaram do potencial desse trabalho para a expansão de nossa visão de mundo e ressignificação de valores. Novamente, a contribuição de um participante auxiliou sobremaneira para a ampliação do diálogo. Um dos cursistas indígenas dissertou sobre o papel da mulher e dos mitos para o seu povo, comentando como essas histórias lhes ajudam a compreender a realidade, sem deixar de lado a espiritualidade.

A segunda vertente da literatura indígena atual foi abordada com os textos Pedrito, de Francisco Cardoso, e Los tres Hermanos, de Domingo Heredia, dois autores argentinos, pertencentes a dois povos distintos, Diaguita e Huarpe, respectivamente. Pedrito narra a história do filho caçula que vivia sendo trapaceado por seus dois irmãos maiores. Em uma oportunidade de vingança, o menino afirmou aos irmãos que sua mãe estava doente que acabara de deixá-la na beira do rio descansando. Chegando lá, os mais velhos viram um objeto no meio do riacho e acreditaram ser sua mãe. Por não saberem nadar, ambos morreram afogados pela trapaça de Pedrito. Por sua vez, Los tres Hermanos conta a história de três irmãos que viviam contando mentiras para obter benefícios próprios. Um deles, sendo mais esperto, envenenou a cabeça do rei contra os outros dois, pois afirmava que eles eram trapaceiros. Após serem pegos pela realeza, estes dois foram queimados vivos em uma fogueira enquanto o outro irmão foi viver no palácio como benfeitor. 
Em comparação à vertente anterior, tanto as temáticas quanto os enredos são completamente diferentes, ocupando-se de problemáticas sociais, peripécias, espertezas e morte (assassinato). No momento do debate, muitas/os participantes comentaram o quanto se surpreenderam com as obras, tanto em função da complexidade quanto das temáticas, pois fogem da tradição anterior (resgate de valores, natureza etc.), mais conhecida de todos.

$\mathrm{Na}$ avaliação do grupo, a seleção das obras contribuiu grandemente para seu conhecimento e para a ressignificação de suas compreensões sobre as identidades e as literaturas indígenas, ampliando olhares e desconstruindo preconceitos. Sobre isso, a cursista $\mathrm{H}$ comentou a importância do contato com produções indígenas, pois "é o indígena falando por si mesmo, diferente de obras indigenistas que muitas vezes romantizam a coisa, que não é por ser literatura indígena que temos que ler apenas temas relacionado à natureza". Em outra fala na mesma direção, a professora universitária e cursista G declarou como "é bom ler obras diferentes para discutirmos de fato o que é ser indígena e como é a sua literatura, assim, dando ênfase ao ensino de língua espanhola em uma dimensão intercultural".

No final do encontro, foi realizado um paralelo entre os quatro textos, visando contribuir para a compreensão das identidades indígenas plurais, momento em que um participante indígena se posicionou (Cursista A), dizendo que gostou 'muito da 'aula' $e$ que a discussão estaria ajudando no entendimento e na quebra de estereótipos do seu povo", comentário que corrobora nossa argumentação do quanto a literatura e cursos da natureza do que estamos descrevendo têm potencial para o diálogo intercultural tão necessário em nossa sociedade.

\section{$3^{\circ}$ Encontro}

O terceiro encontro, realizado no dia 28/07/2020, foi dividido em duas grandes partes: discussão de obras selecionadas e conversa com uma palestrante indigenista convidada. O objetivo central do encontro seria estreitar o diálogo entre saberes indígenas e indigenistas, a partir das obras e de vivências.

Na primeira metade do encontro, fora discutida a lei número 11.645 (BRASIL, 2008), que estabelece a obrigatoriedade da inserção da história e cultura afro-brasileira e indígena em toda a grade curricular. Algumas/alguns participantes professoras/es da educação básica comentaram sobre a não aplicação da referida lei, especialmente em função do despreparo e do desconhecimento das/os docentes sobre questões indígenas, indicando que a realidade denunciada por Graúna (2011) ainda não mudou como Revista X, v. 16, n. 6, p. 1861-1887, 2021. 
gostaríamos, embora consigamos ver avanços, como ilustram Oliveira e Candau (2010), em tom mais otimista.

Em decorrência do despreparo, da falta de familiaridade e do racismo estrutural do qual nossa sociedade se constitui, segundo o grupo, é comum que a questão indígena seja trabalhada exclusivamente na semana do "índio", ainda de forma muito estereotipada. Outro dos participantes indígenas ponderou sentir que muitas/os brasileiras/os sabem mais das questões culturais de outros países que do próprio Brasil. Diante dessa realidade, várias/os cursistas indicaram a relevância de grupos de estudo como o nosso de modo a favorecer não apenas o cumprimento da lei, mas também o estreitamento de laços entre diferentes comunidades, o respeito aos povos originários e o conhecimento de outras formas de ser e saber.

Após essa etapa, foi retomado o diálogo sobre a importância dos mitos para a preservação das memórias, a compreensão das pluralidades identitárias indígenas e suas cosmovisões. A obra "Histórias indígenas dos tempos antigos", de Pedro Cesarino (Brasil), contribuiu sobremaneira para a discussão sobre as questões de Nhamandu e a formação do mundo, pertencente à cosmovisão Guarani (trabalhamos principalmente os Guarani M'byá). Nesse momento, ao discutir questões relacionadas ao mito, o esposo de uma participante (Cursista L), que é pertencente ao povo em questão, pediu para participar, trazendo contribuições riquíssimas.

O novo participante destacou a escolha da obra discutida, por considerá-la significativa para representar seu povo, e apontou o dever do cuidado com os termos usados ao tratar de questões indígenas, explicando, por exemplo, ser mais assertivo o uso de histórias originárias em detrimento a mitos e folclores, que comumente contribuem para a desvalorização das culturas indígenas e a redução dos povos indígenas a identidades estereotipadas. Ele alertou sobre o quanto vivemos a partir de apagamentos e essencializações, ilustrando essa realidade com o fato de indígenas serem convidadas/os apenas para tratar de questões indígenas. Nesse sentido, salientou a imprescindibilidade do resgate das histórias e do conhecimento da ancestralidade e a importância da nomeação de cada povo para indicar a pluralidade: os Guarani; os Kaingang, etc. Enfim, estimulou nossa autoconsciência e reforçou o convite para pensar com os povos indígenas. Sua fala nos lembra Walsh (2009), que escreve e age "por um pensar e agir pedagógicos fundamentados na humanização e descolonização; isto é, no re-existir e re-viver como processos de re-criação" (WALSH, 2009, p.38).

No intervalo do encontro, a cursista $G$ expôs suas contribuições para questões interculturais e uma troca de materiais e produções foi iniciada, contribuindo para o 
estabelecimento de relações mais próximas entre as/os participantes. Essa interação favoreceu a introdução da obra de Nelson Florentino "Histórias de um Guarani" (Brasil). Neste momento, muitas/os cursistas se pronunciaram dissertando tanto sobre os aspectos estilísticos como temáticos dos cinco contos selecionados. $\mathrm{O}$ cursista $\mathrm{A}$, também membro da nação Guarani, se posicionou, agradecendo o debate de autores de seu povo, e como a obra selecionada simboliza a luta, tradição, valores e costumes dos Guarani M’byá.

Nesse encontro, com o intuito de enriquecer o diálogo, recebemos uma linguista, que compartilhou com o grupo suas pesquisas, frutos de vivências em duas comunidades indígenas distintas, com o povo Guarani no estado do Paraná e com uma comunidade indígena mexicana do povo P'urhépecha, onde passou um tempo, por ter conseguido uma bolsa de financiamento de pesquisa. Por meio de fotos, a convidada apresentou seu estudo, suas experiências, sua percepção acerca das semelhanças e diferenças entre os grupos com que teve contato e, sobretudo, nos mostrou como é possível estabelecer um diálogo "com" em detrimento à pesquisas "sobre" os povos indígenas. Em uma fala, a convidada ponderou: "indígenas não são alienígenas".

O encontro foi encerrado com muitas mensagens positivas das/os cursistas, enaltecendo as discussões e as participações do esposo da Cursista L e da linguista convidada. Um dos cursistas enviou mensagem emocionado, declarando o quanto estava satisfeito em ver uma comunidade se constituir em um curso de extensão e o quanto esse tipo de ação precisa ser valorizada, ampliada e divulgada.

\section{$4^{0}$ Encontro}

Para esse encontro estava programada a leitura de duas obras, introduzindo à questão indigenista. Contudo, a partir da interação da participante convidada e do esposo indígena da cursista, em diálogo, enquanto proponentes e ministrantes do curso, decidimos mudar um pouco o direcionamento a fim de abrir espaço para que as discussões fomentadas pelas leituras pudessem ser mais aprofundadas e enriquecidas com as vivências, trajetórias, saberes, visões e reflexões das/os integrantes do grupo. Avaliamos ainda que essa abertura poderia contribuir para o fortalecimento da comunidade que se formava e teria potencial para fomentar outros trabalhos conjuntos, significativos para todas/os. Assim, decidimos convidar dois dos cursistas para compartilharem um pouco mais sobre suas narrativas de vida. Para que isso fosse possível, dividimos esse quarto encontro em duas partes: discutir apenas uma das obras programadas e ouvir estes dois cursistas.

Sobre a obra selecionada, "La guerra de los yacarés", de Horácio Quiroga (Uruguai), discutimos como a temática, o enredo e a construção narrativa se relacionam 
diretamente com a luta dos povos indígenas. Anteriormente, debatemos, a partir de dois textos distintos publicados no mesmo ano, um equatoriano (GUAYASAMÍN MOGROVEJO, 2013) e outro da Espanha (ALEMANY BAY, 2013), como diferentes teóricas/os indigenistas abordam a questão indígena. O primeiro deles traz um olhar mais decolonial ${ }^{3}$, com a valorização cultural e um cuidado maior com o léxico utilizado. Por sua vez, ainda que numa tentativa assertiva, a visão eurocêntrica e colonizadora se evidenciou no texto europeu, inclusive empregando muitas vezes o vocábulo "índio", dotado de uma carga negativa e altamente pejorativa. O intuito do trabalho com a obra era ilustrar como as armadilhas da colonialidade podem se fazer presentes, mesmo em tentativas de contribuir com a luta indígena. Diante dessa realidade, destacamos a necessidade de um olhar crítico no momento de eleger as obras a serem levadas para a sala de aula e a importância da formação docente para que a obra seja abordada de forma a contribuir para a interculturalidade e não para o reforço de estereótipos. A adoção de textos escritos por autoras/es indígenas pode contribuir para a não reprodução de narrativas únicas e impostas sobre os povos originários. Sobre essa parte das discussões, a cursista F conclui que "é preciso abalar as estruturas! Essa mudança de olhar é uma prática difícil, embora necessária".

Nas discussões sobre o texto de Quiroga, que narra a chegada de navios patrulheiros em territórios anteriormente habitados apenas por peixes e jacarés, alguns dos posicionamentos elucidam a criticidade das/os participantes, apontando que a obra é uma perfeita alusão à invasão das terras que vieram a se chamar América e Brasil pelos colonizadores europeus. Em um dos depoimentos, uma cursista não indígena (Cursista E) pondera que "a obra reflete a questão da colonização de uma maneira bem clara e profunda, fazendo com que reflitamos a questão da invasão desde a perspectiva dos que aqui estavam". Em outra fala, um outro participante (Cursista D) analisa que "o texto, embora datado do início do século passado, é muito atual e necessário de se discutir". Outras duas colocações reforçam o quanto textos que dialogam com a luta indígena precisam ser levados à sala de aula para que possamos olhar para a história desde uma outra perspectiva, mais além da imposta e enraizada na narrativa única (GRAÚNA, 2011; ADICHIE, 2009) sobre o "descobrimento":

\footnotetext{
${ }^{3}$ Os estudos decoloniais, em linhas muito gerais, se constituem como um movimento que tem por objetivo fazer frente, sobretudo, ao imperialismo eurocêntrico e às concepções dominantes da modernidade. Desta forma, visam debater as feridas do colonialismo e denunciar a necessidade de superação da colonialidade de poder e de saber (QUIJANO, 2005) e do ser (WALSH, 2009), dentre outras questões.
} 
- A obra faz uma analogia com a chegada do homem branco em territórios não pertencentes à eles, sem se importar com os reflexos desse avanço; as armas que ambos lados dispunham é desigual; os jacarés, aludindo aos indígenas, estavam indefesos; a obra não é habitual, pois as literaturas indigenistas, em linhas gerais, romantizam a questão indígena; reflete a cosmovisão e tradição indigena (Cursista I);

- Que a união dos jacarés é o símbolo de resistência indígena ao largo dos séculos de colonização, anulação dos seus direitos, incluso de viverem conforme sua visão de mundo (Cursista J).

Após estas discussões e dialogando com o texto de Horácio Quiroga, com vistas a ilustrar a luta dos povos indígenas por demarcação e preservação de seus territórios, apresentamos algumas reportagens latino-americanas atuais, principalmente matérias que retratam a questão do avanço de mineradoras em terras demarcadas. Consideramos que essas discussões unem esforços a processos decoloniais, que denunciam as colonialidades de ser, poder e saber, processos que negam o estatuto de humano para africanos e indígenas (WALSH, 2009).

Feito isto, foram iniciadas as falas dos convidados cursistas. O primeiro, um participante argentino, doravante Cursista $\mathrm{K}$, destacou seu orgulho por sua ancestralidade ao mesmo tempo que denunciou o desrespeito aos povos indígenas da cidade e expôs a dor indígena, a necessidade de reconhecimento das diferentes identidades, da miscigenação entre os povos, da desconstrução de estereótipos. O cursista expôs sua vivência junto a comunidades indígenas no seu país e falou de seu trabalho com pessoas refugiadas e migrantes, também por pertencer a este grupo, destacando a necessidade de se colocar no lugar do outro, de proteger a vida, valorizar costumes e línguas. Por fim, o participante apontou o quanto as literaturas indígenas podem contribuir para essas questões.

Encerrando sua participação, o convidado leu dois de seus poemas que narram a luta de indígenas, migrantes e refugiadas/os, emocionando o grupo todo, como ilustra o comentário da cursista C: "não esperava me emocionar e chorar no encontro de hoje". Embora tenhamos programado a fala de dois cursistas, o segundo convidado gentilmente cedeu espaço para que o primeiro concluísse sua exposição. Entendemos esse processo de ser tocada/o pela história da/o outra/o, tanto indicado pelo cursista que cedeu seu espaço quanto pelos comentários de outras/os participantes, como parte importante do processo de transformação, no qual 
o amor constitui-se como aparato político e existencial, como componente central de uma consciência dissidente e criativamente insurgente que pode intervir (e insurgir) tanto no interior como nas relações modernas/coloniais/neoliberais que mantêm a dominação e desumanização (WALSH, 2009, p. 38-39).

\section{$5^{\circ}$ Encontro}

Dando continuidade aos trabalhos, o quinto encontro marca o momento de debate com a obra principal do curso: o texto "Sujuy k'iin: día sin mancha", de Sol Ceh Moo, escritora mexicana do povo Maia Yacuteca. Cabe pontuar que, em todas as leituras discutidas, o ministrante trouxe dados sobre o lugar de fala dos autores, a que povo pertence, sua luta e como a luta, visão e saberes do seu povo se refletem em suas publicações. Ademais, é assertivo dizer que todos os textos anteriores dialogam com a novela de Ceh Moo, por isso a sua eleição neste momento. Após o debate, o participante do encontro anterior faria sua exposição.

Foram solicitados a/os participantes posicionamentos a respeito das seguintes questões: percepção da obra; cosmovisão Maia; estilos de escrita; mescla de temáticas; o papel da mulher Maia; cristianismo x espiritualidade; respeito aos mais idosos; como a obra favorece a ressignificação da identidade indígena contemporânea; outros pontos destacados. Os excertos a seguir ilustram as manifestações das/os cursistas:

- Na obra, fica evidenciado que na tradição indígena a mulher não é submissa ao homem. Essa condição emergiu a cargo do contato entre culturas, sobretudo com não-indígenas (Cursista J);

- O papel da mulher maia é ocidentalizado (Cursista K);

- A narrativa é maravilhosa; ao passo que nos entretém, nos faz refletir sobre problemáticas sociais, como as drogas, o alcoolismo, etc. (Cursista B);

- A luta da mulher e dos povos é legítima (Cursista L);

- A identidade indígena é atravessada pela história e pelos contatos, mudando o seu modo de viver e de ser (Cursista F);

- No direito do indígena à literatura, aparece também o direito de mostrar as raízes das tradições do país. Muito bacana. Amei o livro (Cursista C);

- Agradeço a oportunidade de ler autoras indígenas como a Sol Ceh Moo, professor. Obra riquíssima em reflexões e problematização sobre os lugares, sóciohistoricamente construídos, que as mulheres ocupam, suas resistências e lutas 
para subverter as naturalizadas opressões patriarcais. A figura de Socorro, filha de Mila, me trouxe muita reflexão. Sobre o próximo encontro, estou de acordo e acho muito bacana a sugestão (Cursista $G$ ).

Neste momento, um dos cursistas indígenas se posicionou da seguinte maneira:

São entendiveis e aceitáveis todas as questões que a autora evoca, sobretudo da religiosidade e a aparente pacificação nas relações entre indígenas e o branco. Mas digo ser aparente pois não se pode esquecer de toda a luta, sofrimento e dor que os indigenas passaram e continuam a passar, seja pela imposição de culturas, da língua, da religiosidade, seja por modos de viver. E mais, ainda que esse novo modo de viver seja incorporado no cotidiano indígena, estes hábitos foram violentamente forçados (Cursista A).

O cotejamento dos comentários realizados nesse encontro com o texto do encontro anterior, de Horacio Quiroga, indica a tentativa de olhar contra/decolonial, principalmente no que tange a necessidade de legitimar nossas discussões com a presença de representantes indígenas, em um diálogo "com eles e para eles." Entendemos que a eleição da literatura indígena é assertiva para iniciar um movimento decolonial.

O segundo participante a fazer sua fala ao grupo, doravante Cursista M, é docente em uma instituição universitária pública, doutorando e orgulhosamente indígena por descendência; fez sua fala em um discurso bastante politizado, analisando de forma crítica o espaço do indígena na sociedade brasileira, na política, na educação, na literatura e nas mídias. O participante destaca que a literatura indígena pode contribuir para que estereótipos sejam diminuídos, corroborando nosso posicionamento. Fora um momento de conscientização, emoção e empatia para com os povos originários.

Para elucidar alguns dos feedbacks recebidos via interação no chat da plataforma Teams, destacamos:

- Eu queria agradecer por esse grupo de estudos. E queria agradecer humilde e imensamente os colegas Cursista L e Cursista $M^{4}$ por nos ajudarem a descolonizar nosso pensamento e nos desconstruir como racistas que fomos constituidos;

- Tu voz es lucha, tu voz me inspira, quiero gritar porque también violentaron mi existencia al no darme posibilidad de conocer nuestras raíces, pero estamos al

\footnotetext{
${ }^{4}$ Ambos são participantes indígenas. 
tiempo de ser una y muchas voces. Gracias por hablar, gracias por estar en este grupo. Gracias Prof. por acercarnos (Cursista K).

$\mathrm{O}$ encontro foi encerrado com a mensagem do cursista M: "Branco não é cor de pele, é de pensamento e atitudes". Essa fala encontra eco nos estudos sobre raça, que têm denunciado veemente o racismo estrutural no qual nossa sociedade se constitui, que valoriza certos corpos enquanto apaga e inviabiliza outras vidas (FANON, 2008).

\section{$6^{0}$ Encontro}

Para o último encontro, fora programado um Sarau de encerramento. Cada participante ficou responsável por trazer suas sugestões de leitura, obras, textos, canções e/ou outra manifestação artístico-cultural indígena, seja em língua espanhola, portuguesa, língua originária etc. As sugestões seriam futuramente compiladas pelo ministrante em forma de "livro" para socialização entre os cursistas e/ou quem se interessar pelas leituras.

Cada cursista recitou/leu/declamou a sua contribuição e foram discutidos os seguintes temas: "índio" eu não sou; saberes ancestrais; mãe terra; respeito à natureza; vida e morte; sonhos e lutas; valorização da identidade; diversidade; afeto; luta, entre tantos outros. Foram contribuições nas línguas portuguesa, indígenas e em espanhol, evocando variados povos originários latino-americanos. Abaixo, algumas das contribuições (autoria - título da obra):

- Márcia Kambeba: Índio eu não sou;

- Pierre Clastres: A fala sagrada: mitos e cantos sagrados dos indios Guarani;

- Lina Gutierrez: Pachamama, la Tierra Madre;

- Graciela Huinao: La vida y la muerte se hermanan;

- Daniel Iberê: Sobre Palavras e Parentes Ou para além de humanos e nãohumanos;

- Pablo Neruda: Las agonías;

- Nora Alarcón: Canto;

- Davi Kopenawa: A queda do céu: Palavras de um xamã Yanomami.

$\mathrm{O}$ encontro se encerrou com agradecimentos mútuos. A imagem 1 elucida as palavras que representam o curso sob o olhar das/os participantes (feito em tempo real através do aplicativo https://www.menti.com/). 
Imagem 1: Feedback recebido em tempo real no último encontro.

\section{Defina o curso em uma única palavra:}
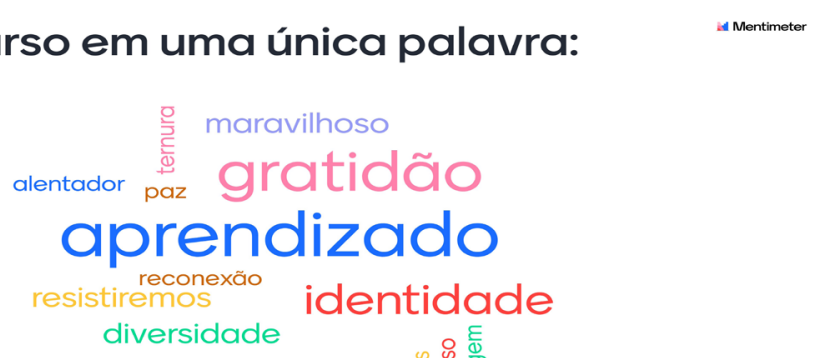

Fonte: os autores.

\section{AVALIAÇÃO GERAL DO CURSO}

Inicialmente, cabe destacar a quantidade de inscritos no curso: 282, refletindo tanto a pertinência dos cursos livres ofertados no âmbito de nosso programa de pósgraduação como, e principalmente, da temática proposta. Cabe pontuar que a oferta dos cursos livres foi amplamente divulgada e as/os participantes deveriam se candidatar a uma das 40 vagas preenchendo um formulário eletrônico. Desse número de inscrições, 43 foram matriculadas/os: 41 inscritas/os e 2 palestrantes convidadas/os. A recomendação foi de eleger as inscrições por ordem de candidatura.

Assim, ante o descrito nos encontros, pelos feedbacks recebidos e pelo percentual de participação das/os cursistas matriculadas/os, salientamos a relevância das discussões apresentadas. Dentre os temas mais abordados, destacam-se a necessidade de decolonizar saberes; conhecer o lugar de fala do outro; da necessidade da não-estereotipação e homogeneização das identidades plurais dos diferentes povos originários e, sobretudo, do quanto a literatura indígena e indigenista em espanhol pode favorecer o conhecimento e as discussões de todas estas questões.

Do total de cursistas que foram matriculadas/os, 26 participantes (61\%) concluíram com mais de $75 \%$ de participação; $23 \%$ comunicaram desistência por força maior e somente $16 \%$, embora matriculadas/os, não compareceram aos encontros. Contudo, apontamos que maior que qualquer dado quantitativo é a riqueza de discussões que emergiram em cada um dos encontros da oficina. Em nossa avaliação, o curso possibilitou a reunião 
e a formação de um grupo de pessoas que discutem a luta dos povos indígenas, entre outras questões relacionadas, de forma engajada. O comprometimento das/os cursistas foi além do esperado, com participações ativas nos encontros e leituras atentas, críticas e dialógicas dos textos selecionados. Assim como apontado no encontro de encerramento, muito embora em um período pandêmico e de todas as decorrências desse momento, os números mostram que é válido e necessário discutirmos questões indígenas em um diálogo constante com os diferentes povos, sua luta, suas necessidades, etc.

Ante o exposto em todo esse relato, concluímos que todos os objetivos do curso foram mais que satisfatoriamente alcançados, contribuindo para a disseminação dos saberes, da proposta do curso e da pertinência e visibilidade dos cursos livres em âmbito de pós-graduação, contribuindo para a disseminação e ampliação de saberes, em uma perspectiva de ecologias de saberes, como proposto por Santos (2007).

\section{ALGUMAS CONSIDERAÇÕES: RETORNO}

Mais que o atendimento de uma Lei que torna obrigatório a inserção da cultura e história afro-brasileira e indígena no âmbito escolar (BRASIL, 2018), acreditamos que tanto este relato quanto o curso de extensão ministrado são possibilidades de narrar dias melhores, unir forças e engrossar movimentos contra/decoloniais. Fomentando a leitura e discussão de textos literários indígenas e indigenistas latino-americanos em língua espanhola, o curso procurava abrir espaço de diálogo com diferentes autoras/es indígenas e indigenistas. Defendemos que esse trabalho tem potencial para contribuir com a aproximação, valorização e conhecimento acerca das lutas, modos de ser, pensar e agir dos diferentes povos originários.

Os resultados de nossa ação e os comentários transcritos ao longo do texto apontam para a construção coletiva de um espaço para conhecer, compartilhar e discutir temáticas, lutas, saberes e cosmovisões indígenas plurais. Diante desses resultados, finalizamos defendendo que cursos extensionistas como foi o Leitura e discussão de obras indígenas e indigenistas em espanhol podem ser uma alternativa para que trabalhemos questões inerentes aos indígenas e suas especificidades, dentro de uma perspectiva intercultural, em movimento de resistência e re-existência. Além disso, a partir de nossas vivências, apontamos a necessidade de dialogar e construir conjuntamente, ouvindo, aprendendo e estabelecendo laços.

Esse estar junto, assim como relatado, vai nos modificando, ampliando e estabelecendo novos olhares, novas lentes, e fortalecendo as reivindicações por um mundo onde caibam muitas formas diferentes de vida. Movimentos de re-existências Revista X, v. 16, n. 6, p. 1861-1887, 2021. 
causam deslocamentos e trazem conquistas e mudanças fundamentais. Finalizamos nosso texto em um contexto de luto, com mais de 550 mil vidas perdidas para a covid19, dentre as quais muitas indígenas. Contexto desolador, mas também marcado por ebulição política e social, com manifestações contrárias ao governo atual bem como às histórias hegemônicas que foram contadas como únicas por muito tempo.

Nesse contexto, não poderíamos finalizar o texto sem mencionar o fato de a estátua de Borba Gato ter sido incendiada quando finalizávamos nosso relato. O derrubamento de monumentos dos considerados "heróis nacionais" dentro da perspectiva de narrativas únicas, que trazem à tona o olhar do colonizador, do opressor, se constituem como atos políticos dos que sofreram e sofrem, pois esses mesmos "heróis" simbolizam, também, a morte de muitos corpos escravizados e impedidos de viver. Nesse sentido, indicamos o derrubamento da estátua de Borba Gato como um marco em nossa história, que nos desloca e nos convoca a ler a história com outras lentes, buscando compreender as razões que motivam essa ação como movimento de re-existência. É a partir de aproximações e questionamentos que nos inserimos em diálogos interculturais e epistêmicos, tão necessários nos dias atuais.

\section{REFERÊNCIAS}

ADICHIE, C. N. The danger of a single story. TED talk. 7 out. 2009. Disponível em: https://www.youtube.com/watch?v=D9Ihs241zeg. Acesso em: 12 set. 2021.

ALEMANY BAY, C. La narrativa sobre el indígena en América Latina. Fases, entrecruzamientos, derivaciones. Acta Literaria no 47, II Sem. (85-99), 2013. Disponível em: https://www.redalyc.org/pdf/237/23729666006.pdf. Acesso em: 16 ago. 2021.

BACK, R.; BEATO-CANATO, A. P. M.; AMORIM, M.A. Etno-histórias nas escolas brasileiras: um caminho de aproximação com os povos indígenas. Gragoatá, Niterói, v.26, n.56, p. 1018-1051, 2021. <https://doi.org/10.22409/gragoata.v26i56.49151> 
BRASIL. Constituição da República Federativa do Brasil. Brasília: Senado Federal, 1988.

BRASIL. Lei $\mathbf{n}^{0} \mathbf{1 0 . 6 3 9}$, de 9 de janeiro de 2003. Altera a Lei no 9.394 , de 20 de dezembro de 1996, que estabelece as diretrizes e bases da educação nacional, para incluir no currículo oficial da Rede de Ensino a obrigatoriedade da temática 'História e Cultura Afro-Brasileira', e dá outras providências. Diário Oficial da União, Brasília, 10 jan. 2003.

BRASIL. Lei no 11.645. Altera a Lei n ${ }^{\circ}$ 9.394, de 20 de dezembro de 1996, modificada pela Lei ${ }^{\circ} 10.639$, de 9 de janeiro de 2003, que estabelece as diretrizes e bases da educação nacional, para incluir no currículo oficial da rede de ensino a obrigatoriedade da temática "História e Cultura Afro-Brasileira e Indígena". Diário Oficial da República Federativa do Brasil, Brasília, 2008.

CARDOSO, F. Pedrito. In: VIDAL DE BATTINI, B. Cuentos y leyendas populares de Argentina. Tomo VI. Buenos Aires: Ediciones Culturales Argentinas, 1980, p. 593-595.

CEH MOO, S. Sujuy k’iin: día sin mancha. México: Instituto de Cultura de Yucatán, 2011.

CESARINO, P. Histórias indígenas em tempos antigos. São Paulo: Claro Enigma, 2015.

FANON, F. Pele negra, máscaras brancas. Tradução de Renato da Silveira. Salvador: EDUFBA, 2008.

FLORENTINO, N. Histórias de um Guarani. Ponta Grossa: Todapalavra Editora. 2019.

GRAÚNA, G. Literatura Indígena no Brasil contemporâneo e outras questões em aberto. Educação \& Linguagem, v. 15, n. 25, pp. 266-276, jan.-jun. 2012. Disponível em: https://www.metodista.br/revistas/revistas-ims/index.php/EL/article/view/3357. Acesso em: 16 ago. 2021.

GUAYASAMÍN MOGROVEJO, M. N. Acusación y defensa de la literatura indigenista. Resistencia: Revista de los estudiantes de la Universidad Andina Simón Bolívar, Sede Ecuador. 3 (diciembre 2013): 35-37. Disponível em: http://hdl.handle.net/10644/4352. Acesso em: 16 ago. 2021.

HALL, S. A identidade cultural na pós-modernidade. Trad. Tomaz Tadeu da Silva e Guacira Lopes Louro. 12 ed. Rio de Janeiro: Lamparina, 2015 [1992]. 
HEREDIA, D. Los tres hermanos. In: VIDAL DE BATTINI, B. E. Cuentos y leyendas populares de Argentina. Tomo VI. Buenos Aires: Ediciones Culturales Argentinas, 1980, p. 596-600.

LA NIÑA DEL RÍO. Basado en un cuento de tradición popular Chinanteco. Adaptación: Alicia Gregorio Velasco y Gabriela Badillo. Disponível em: https://68voces.mx/ chinantecola-\%20nina-del-rio. Acesso em: 16 ago. 2021.

OLIVEIRA, L. F.; CANDAU, V. M. F. Pedagogia Decolonial e educação antirracista e intercultural no Brasil. Educação em Revista. Belo Horizonte, v. 26, n.1, p. 15-40, abr. 2010 .

QUIJANO, A. Colonialidade do poder, eurocentrismo e América Latina. In: LANDER, E. (Org.). A colonialidade do saber: eurocentrismo e ciências sociais: perspectivas latinoamericanas. Buenos Aires: Consejo Latinoamericano de Ciencias Sociales, 2005.

QUIROGA, H. La guerra de los yacarés. In: QUIROGA, H. Cuentos de la selva. $1^{\text {a }}$ edición especial - Ciudad Autónoma de Buenos Aires: Ministerio de Educación de la Nación, 2018.

SANABRIA, L. N. El maíz. In. SANABRIA, L. N. Lengua Guaraní. Asunción: Diccionário Arami Grupo Empresarial, 2002, p. 722.

SANTOS, A. B. D. Colonização, quilombos: modos e significações. Brasília; INCT/ UnB, 2015.

SANTOS, B. S. Para além do pensamento abissal: das linhas globais à ecologia de saberes. Revista Crítica de Ciências Sociais, n. 78, p. 3-46, 2007. Disponível em: https://journals. openedition.org/rccs/753. Acesso em: 16 ago. 2021.

SILVA, G. J; COSTA, A. M. R. F. M. Histórias e culturas indígenas na Educação Básica. Belo Horizonte: Autêntica, 2018.

SOUZA, A. L. S. Letramentos de reexistência - poesia, grafite, música, dança: hip-hop. São Paulo: Parábola Editorial, 2011.

WALSH, C. La education Intercultural en la Education. Peru: Ministerio de Educación. (documento de trabalho), 2001.

WALSH, C. Introducción - (Re)pensamiento crítico y (de)colonialidad. In: WALSH, C. Pensamiento crítico y matriz (de)colonial. Reflexiones latinoamericanas. Quito: Ediciones Abya-Yala, 2005, p. 13-35. 
WALSH, C. Interculturalidade crítica e Pedagogia Decolonial: in-surgir, re-existir e re-viver. In: CANDAU, V. M. F. Educação Intercultural na América Latina: entre concepções, tensões e propostas. Rio de Janeiro: Viveiros, 2009, p. 12-42.

Recebido em: 27 de jul. 2021. Aceito em: 13 set. 2021. 